\title{
Model development to enhance the solvent extraction of rice bran oil
}

\author{
Fajriyati Mas'ud ${ }^{1, *}$, Fajar $^{1}$, Herman Bangngalino ${ }^{1}$, Sri Indriati ${ }^{1}$, Abigael Todingbua ${ }^{1}$, Suhardi ${ }^{2}$ \\ and Muhammad Sayuti ${ }^{3}$ \\ ${ }^{1}$ Department of Chemical Engineering, Politeknik Negeri Ujung Pandang, Makassar, South Sulawesi, 90245, Indonesia \\ 2 Department of Agricultural Engineering, Hasanuddin University, Makassar, South Sulawesi, 90245, Indonesia \\ ${ }^{3}$ Department of Animal Husbandry, Agricultural Faculty, Gorontalo State University, Gorontalo, 96128, Indonesia
}

Received 4 November 2018 - Accepted 4 March 2019

\begin{abstract}
Rice bran oil (RBO) extraction with ethanol using maceration method accompanied by stirring has been optimized using response surface methodology (RSM) based on central composite design (CCD). Experiments were conducted to investigate the influence of extraction time, ethanol concentration, and ethanol volume on the oil yield, $\gamma$-oryzanol, and vitamin E of RBO as the response. The experiment consisted of twenty units including six replicates of the center points. The data were analyzed using DesignExpert 10 software to develop and evaluate models and to plot the response curve as 3D surfaces. The result showed that the maximum of the oil yield, $\gamma$-oryzanol, and vitamin E of RBO was achieved under the optimum conditions of $x_{1}=5.30 \mathrm{~h}, x_{2}=89.21 \%$ and $x_{3}=686.66 \mathrm{~mL}$ (50 g rice bran), respectively. Maximum of the response under these conditions was $14.47 \%, 783.65 \mathrm{mg} . \mathrm{L}^{-1}$, and $127.01 \mathrm{mg} . \mathrm{L}^{-1}$, respectively. This study has resulted in the development of a model for RBO extraction using ethanol as solvent, it is feasible to be applied to the RBO industry with an efficient process, as well as an implementation of the "green" solvent concept.
\end{abstract}

Keywords: maceration / edible oil / ethanol / green solvent / response surface methodology

Résumé - Développement d'un modèle pour améliorer l'extraction solvant de l'huile de son de riz. L'extraction de l'huile de son de riz (rice bran oil, RBO) à l'éthanol par la méthode de la macération accompagnée d'une agitation a été optimisée à l'aide de la méthode RSM (response surface methodology) basée sur un plan d'expérience de type composite centré (central composite design, CCD). Des expériences ont été menées pour étudier l'influence du temps d'extraction, de la concentration en éthanol et du volume d'éthanol sur le rendement en huile, en $\gamma$-oryzanol et en vitamine $\mathrm{E}$ de l'huile de son de riz. L'expérience consistait en vingt essais comprenant six réplicats des points centraux. Les données ont été analysées en utilisant le logiciel Design-Expert 10 pour développer et évaluer les modèles et pour tracer la courbe de réponse sous forme de surfaces $3 \mathrm{D}$. Le résultat a montré que le maximum de rendement en huile, $\gamma$-oryzanol et vitamine $\mathrm{E}$ de l'huile de son de riz a été atteint dans les conditions optimales de $x_{1}=5,30 \mathrm{~h}$ d'extraction, $x_{2}=89,21 \%$ d'éthanol et $x_{3}=686,66 \mathrm{~mL}$ de solvant $(50 \mathrm{~g}$ de son de riz). La réponse maximale dans ces conditions était de $14,47 \%$ d'huile, $783,65 \mathrm{mg} . \mathrm{L}^{-1}$ d' $\gamma$-oryzanol et $127,01 \mathrm{mg} . \mathrm{L}^{-1}$ de vitamine E. Cette étude a abouti à la mise au point d'un modèle d'extraction d'huile de son de riz utilisant l'éthanol comme solvant; le process pourrait être appliquée à l'industrie de l'huile de son de riz de manière efficace et en répondant au concept de solvant «vert».

Mots clés : macération / huile alimentaire / éthanol / solvant vert / méthodologie de surface de réponse

*Correspondence: fajri888@poliupg.ac.id 


\section{Introduction}

$\mathrm{RBO}$ is edible oil extracted from rice bran which is a byproduct of rice mills. $\mathrm{RBO}$ is superior among the other edible oils because it contains unique antioxidants and nutraceutical complexes present in its composition (Oliveira et al., 2012). In the unsaponifiable fraction of RBO contains $\gamma$-oryzanol and tocols. These compounds have been reported in the scientific literature as powerful antioxidant agents that are effective for preventing degenerative diseases (Lerma-García et al., 2009). Seema (2015) suggests that bran antioxidants are mainly $\gamma$-oryzanol and vitamin E, as well as unsaturated fats capable of lowering cholesterol. $\gamma$-oryzanol component of RBO was first presumed to be a single component, but later it was determined to be a fraction containing ferulate (4hydroxy-3-methoxy cinnamic acid) esters of triterpene alcohols and plant sterols (Rogers et al., 1993). Cycloartenyl ferulate, 24-methylenecycloartanyl ferulate, and campesteryl ferulate are the three major components of $\gamma$-oryzanol (Xu et al., 2001).

On the other hand, the most important contribution of vegetable oils is their tocopherol content, which is generally collectively referred to as "vitamin E". Vegetable oils contain high concentrations of vitamin E (Bauernfeind and Desai, 1977) and can provide the most daily requirement of vitamin $E$ (Desai et al., 1980). High vitamin E levels in rice bran oils are reported to have antihypocholesterolemic, anticancer, and neuroprotective properties. Tocols are capable of reducing lipid peroxidation and lipid risk factors, in this case increasing LDL cholesterol and platelet aggregation, exhibiting antiinflammatory properties, demonstrating anti-carcinogenic and cardiovascular protection effects (Tiwari and Cummins, 2009).

Some scientific reports on the benefits of RBO for health have led this study to evaluate the optimization of the extraction process of RBO. The direct solvent extraction method, which does not require specific extraction instrumentation, has been most commonly used (Chen and Bergman, 2005), and ethanol has gained attention as a potential solvent for vegetable oils (Rodrigues and Oliveira, 2010). Study on sesame oil revealed that the polar solvent such as ethanol was a good solvent compared to non-polar solvents. According to Péres et al. (2006), these results could be explained by the interaction between the unsaturated fatty acids with a polar solvent, compared with non-polar solvents. In fact, the oils extracted with ethanol presented the typical composition of RBO (Firestone, 1999). Ethanol has attractive advantages to use as a solvent, including low toxicity, good operational security, as well as being obtained from a bio-renewable source (Bessa et al., 2017). The choice of ethanol as a solvent is deemed necessary to implement the concepts and principles of green extraction.

According to Chemat et al. (2012), green extraction is a new concept to protect both the environment and consumers and in the enhanced competition of industries to be more ecologic, economic, and innovative. Within the green extraction approach, the concept of the green extract is an extract obtained in such a way to have the lowest possible impact on the environment. Because of environmental concerns, a suitable solvent which gives less impact to the environment is more preferred nowadays. Further, according to Tekin et al. (2018), ethanol has been widely applied as a viable solvent due to their ease of recovery and low cost in an application and is classified as an environmentally friendly green solvent. Although alcohols such as ethanol, methanol and isopropyl alcohol have similar solvent properties, ethanol has become the foremost among others because of its non-toxic nature. Li et al. (2016) stated that the green solvents have several benefits such as biodegradability, low toxicity, nonflammability, and renewability making them potential candidates in separation science.

Many studies have proven the technical feasibility of employing ethanol in the process of extraction oils (Saxena et al., 2011). On oil extraction from sunflower collets, ethanol gave a higher yield of extracted material, the content of oil phase was similar to that obtained when $n$-hexane is used. When ethanol was used, about $70 \%$ less crystallizable waxes and about 38\% more tocopherols and phospholipids were extracted, this shows the feasibility of using ethanol as an alternative solvent to hexane in extracting oil (Baümler et al., 2016), including RBO (Oliveira et al., 2012; Rodrigues and Oliveira, 2010). Previously, Imsanguan et al. (2008) have reported that ethanol was a better solvent for $\gamma$-oryzanol extraction compared to hexane. It can be explained by the relatively high polarity of the $\gamma$-oryzanol molecule (consisting of triterpene alcohols and phytosterols esterified with ferulic acid), where the polarity of the solvent may significantly affect the extractability of $\gamma$-oryzanol (Xu and Godber, 2001).

Based on the results of the existing study on the RBO, and that the optimization of the extraction process is very much related to production costs, as well as considering the needs of the RBO extraction industry for the pharmaceutical and food industries related to the optimization of the extraction process, then this research was conducted. To the best of the author's knowledge, this is the first study, RBO extraction uses ethanol and monitors the extraction time, ethanol concentration, and volume of ethanol on oil yield, $\gamma$-oryzanol, and vitamin $\mathrm{E}$ of $\mathrm{RBO}$ in the maceration method accompanied by stirring, and applies RSM to optimize the RBO extraction process, standardize, and analyze the resulting model.

\section{Materials and methods}

Ciliwung rice, local rice of Indonesia, as samples were obtained from milling rice grain in a local grinding mill Makassar Indonesia during March to April in 2017. Ethanol (wt.\%) purchased from a local chemical shop, $\gamma$-oryzanol standard from Sigma-Aldrich Co and $\alpha$-tocopherol standard from Sigma, St. Louis, USA. Ethyl acetate, methanol, and chloroform from Merck, Germany.

\subsection{Preparation of rice bran and extraction oil}

Freshly milled bran samples were directly collected from the milling system in polyethylene bags, the rice bran was screened through a 60 -mesh sieve to have a uniform particle size and stabilized at autoclave (Hiclave HV-85 Hirayama) at $100^{\circ} \mathrm{C}$ for $15 \mathrm{~min}$ for inactivating endogenous lipase. For extraction oil, each experimental unit weighed $50 \mathrm{~g}$ of rice bran in the Erlenmeyer $1000 \mathrm{~mL}$, RBO was extracted using maceration method with stirring under the $30^{\circ} \mathrm{C}$ of room 
Table 1. Five levels of independent variables of central composite design.

\begin{tabular}{|c|c|c|c|c|c|}
\hline \multirow{2}{*}{$\begin{array}{l}\text { Independent } \\
\text { variables }\end{array}$} & Star low & Low & Centre & High & Star high \\
\hline & $(-1.68)$ & $(-1)$ & $(0)$ & $(+1)$ & $(+1.68)$ \\
\hline Extraction time (h) & 3.32 & 4 & 5 & 6 & 6.68 \\
\hline $\begin{array}{l}\text { Ethanol concentration } \\
\text { (wt.\%) }\end{array}$ & 69.18 & 76 & 86 & 96 & 100 \\
\hline $\begin{array}{l}\text { Ethanol volume } \\
(\mathrm{mL})\end{array}$ & 431.82 & 500 & 600 & 700 & 768.18 \\
\hline
\end{tabular}

temperature, and pulp was separated by centrifugation (refrigerated AX-521 centrifuge) at a speed of $3500 \mathrm{rpm}$ for $20 \mathrm{~min}$. The liquid part was accommodated in the evaporator flask. Then, the solvent was removed in a Buchi R-215 rotary evaporator equipped V-700 vacuum Pomp speed of $60 \mathrm{rpm}$, the heating temperature was of $35^{\circ} \mathrm{C}$, and the evaporation temperature was of $21^{\circ} \mathrm{C}$. RBO was packaged in a dark glass bottle and stored in a freezer before analysis. The percentage of oil yield was calculated as follows (Sani, 2014):

$$
\text { Oil yield }(\%)=\frac{\text { Weight of oil extracted }(\mathrm{g})}{\text { Weight of sample }(\mathrm{g})} \times 100 \text {. }
$$

\subsection{Analysis of $\gamma$-oryzanol and vitamin E}

Preparation of $\boldsymbol{\gamma}$-oryzanol standard: $0.05 \mathrm{~g}$ of the pure $\boldsymbol{\gamma}$-oryzanol was dissolved in ethyl acetate in a $100 \mathrm{~mL}$ flask, and diluted to respectively 100, 200,300, 400, and $500 \mathrm{ppm}$ at a $50 \mathrm{~mL}$ flask, homogenized by vortex, inserted in the vial GCMS (gas chromatography-mass spectrometry). Preparation of vitamin E standard: $0.05 \mathrm{~g}$ of the pure vitamin $\mathrm{E}$ was dissolved in methanol-chloroform $(1: 1)$ in a $100 \mathrm{~mL}$ flasks, and diluted to respectively $100,200,300,400$, and $500 \mathrm{mg} . \mathrm{L}^{-1}$ at a $50 \mathrm{~mL}$ flask, homogenized by vortex, inserted in the vial GC-MS. Preparation of sample of RBO for $\boldsymbol{\gamma}$-oryzanol analysis: $0.012 \mathrm{~g}$ RBO dissolved in $2 \mathrm{~mL}$ ethyl acetate, homogenized by vortex and inserted into the vial bottle GC-MS. Preparation of sample of RBO for vitamin E analysis: $0.012 \mathrm{~g}$ RBO dissolved in $2 \mathrm{~mL}$ methanol-chloroform $(1: 1)$, homogenized by vortex and inserted into the vial bottle GC-MS.

Quantification of $\gamma$-oryzanol and vitamin $\mathrm{E}$ of $\mathrm{RBO}$ : $\gamma$-oryzanol and vitamin E of RBO were performed on a GCMS QP2010 by Shimadzu equipped with a split/splitless injector. Separations were achieved using a Rxi SH-5Sil MS capillary column ( $30 \mathrm{~m}, 0.25 \mathrm{~mm}$ ID, $0.25 \mu \mathrm{m}$ film thickness). Helium was used as the carrier gas at flow rates of $14.0 \mathrm{~mL} / \mathrm{min}$ and a split ratio of 1:10. The oven temperature was programmed at $110^{\circ} \mathrm{C}$ for a hold of $2 \mathrm{~min}$ and increased to $200^{\circ} \mathrm{C}$ at a rate of $10^{\circ} \mathrm{C} / \mathrm{min}$ and hold at the final temperature for $9 \mathrm{~min}$. LabSolution software was used to control the operation of GC-MS. MS spectra were obtained at range width $\mathrm{m} / \mathrm{z} \quad 40-450$, interface temperature $280^{\circ} \mathrm{C}$, and ion source temperature $200^{\circ} \mathrm{C}$. $\gamma$-oryzanol and vitamin $\mathrm{E}$ of $\mathrm{RBO}$ peaks were identified by comparing their retention time and equivalent chain length with respect to the standards.

\subsection{Experimental design for optimization and statistical analysis}

RSM was employed to optimize the parameters of time, ethanol concentration, and ethanol volume for oil yield, $\gamma$-oryzanol, and vitamin E maximum of RBO on extraction process by maceration method accompanied by stirring. RSM provides the optimal conditions of a process, using multivariate statistical techniques to obtain responses from the observed process variables. RSM consists of mathematical and statistical techniques based on polynomial equations that best suit experimental data to describe the behavior of data sets with the aim of obtaining statistical predictive values (Rafi et al., 2015). It is a rapid analytical approach and more economical (Banga and Tripathi, 2009). Nowadays, the procedures based on the statistical evaluation using RSM are widely used to determine the interaction between the factors that influence reactions for optimization.

The CCD is one of the most effective RSM designs, which are widely used in the study and optimization of the linear, quadratic, and interaction effects of variables on observed responses (Soundararajan et al., 2016). The CCD is still the symmetrical second order experimental design most utilized for the development of analytical procedures (Bezerra et al., 2008). Three independent variables examined in this study were time $(\mathrm{h})\left(x_{1}\right)$, ethanol concentration $(\%)\left(x_{2}\right)$, and ethanol volume $(\mathrm{mL})\left(x_{3}\right)$, while the oil yield, $\gamma$-oryzanol, and vitamin E concentration were considered as response variables. The value of independent variables was determined based on the results of the preliminary study. The middle values for the independent variables were $5 \mathrm{~h}, 86 \%$, and $600 \mathrm{~mL}$, respectively. The lower and upper limits for each treatment were 4 and $6 \mathrm{~h}$ for time, 76 and $96 \%$ for ethanol concentrations, 500 and $700 \mathrm{~mL}$ for ethanol volume (Tab. 1). The CCD consists of 14 experimental points and 6 replications of the center point. Replication of the center point was aims to evaluate the pure error variance as the experimental error and to control the adequacy of the model. To estimate the coefficients of the response function and predict the system's responses, analysis of the experimental results of $\mathrm{CCD}$ was realized using empirical second-order polynomial equations as follows: (Amiri et al., 2018; Keshtegar et al., 2018).

$$
Y=\beta_{0}+\sum_{i=1}^{k} \beta_{i} X_{i}+\sum_{i=1}^{k} \beta_{i i} X_{i}^{2}+\sum_{i=1}^{k-1} \sum_{j=1}^{k} \beta_{i j} X_{i} X_{j}+\ldots e
$$

where, $Y$ is a response, $\beta_{0}$ denotes the constant coefficient; $X_{i}$ and $X_{j}$ the independent factors, $\beta_{i}, \beta_{i i}$, and $\beta_{i j}$ the regression coefficients for the linear, quadratic, and interaction effects, respectively; $k$ the number of variables; and $e$ stands for the statistical error occurring to response $Y$ (Awad et al., 2017).

Statistic software Design-Expert 10 was used to design, analyze, and optimize experimental models. Analysis of variance (ANOVA) was used to validate the statistical significance of the parameters that influence the responses, and the quality of the predicted model (Chan et al., 2017; Mohammed et al., 2018). The coefficient of determination $\left(\mathrm{R}^{2}\right)$ shows the total predictive performance of the model, it represented the validity and fit quality of the model's quadratic polynomials. $\mathrm{R}^{2}$ values are close to 1 , indicating a reasonable adjustment of the model to experimental 
Table 2. Central composite design, showing coded values of independent variables, with observed of yield, $\gamma$-oryzanol, and vitamin E of RBO.

\begin{tabular}{|c|c|c|c|c|c|c|}
\hline Exp. & \multicolumn{3}{|c|}{ Parameters } & \multicolumn{3}{|c|}{ Results } \\
\hline 2 & 1 & -1 & -1 & 14.01 & 728.98 & 121.33 \\
\hline 3 & -1 & 1 & -1 & 11.89 & 733.80 & 123.47 \\
\hline 6 & 1 & -1 & 1 & 14.07 & 762.98 & 123.99 \\
\hline 7 & -1 & 1 & 1 & 16.05 & 755.86 & 122.45 \\
\hline 8 & 1 & 1 & 1 & 13.99 & 783.93 & 124.76 \\
\hline 9 & -1.68 & 0 & 0 & 11.46 & 645.42 & 115.63 \\
\hline 10 & 1.68 & 0 & 0 & 10.95 & 882.11 & 124.38 \\
\hline 14 & 0 & 0 & 1.68 & 15.29 & 584.87 & 125.44 \\
\hline 15 & 0 & 0 & 0 & 13.49 & 738.25 & 126.20 \\
\hline 16 & 0 & 0 & 0 & 11.98 & 823.64 & 128.43 \\
\hline 17 & 0 & 0 & 0 & 12.78 & 804.40 & 126.45 \\
\hline 18 & 0 & 0 & 0 & 13.73 & 813.03 & 127.03 \\
\hline 19 & 0 & 0 & 0 & 13.62 & 900.01 & 129.83 \\
\hline 20 & 0 & 0 & 0 & 13.38 & 782.93 & 126.45 \\
\hline
\end{tabular}

data. A $p$-value of $\leq 0.05$ at a confidence level of $95 \%$ and a $F$-value of the lack-of-fit test were used for statistical analysis to evaluate the significance of model statistics, at a confidence level of $95 \%$ and a $F$-value of the lack-of-fit test were used for statistical analysis to evaluate the significance of model statistics (Tan et al., 2017).

\section{Results and discussion}

Extraction of edible oil is generally a multi-parameter process so that the optimization of the process conditions represents a critical step in the development of the model. In the present study, RSM has been used as a tool to develop the model of RBO extraction apply maceration method with stirring to see the effect of $x_{1}, x_{2}$, and $x_{3}$ on the oil yield (\%), $\gamma$-oryzanol $\left(\mathrm{mg} . \mathrm{L}^{-1}\right)$, and vitamin $\mathrm{E}\left(\mathrm{mg} . \mathrm{L}^{-1}\right)$ of RBO. The effects of $x_{1}, x_{2}$, and $x_{3}$ on the yield of oil (\%), $\gamma$-oryzanol $\left(\mathrm{mg} . \mathrm{L}^{-1}\right)$, and vitamin $\mathrm{E}\left(\mathrm{mg} . \mathrm{L}^{-1}\right)$ of $\mathrm{RBO}$ have been studied during experimentation. The data results of 20 runs using a CCD showed that oil yield, $\gamma$-oryzanol, and vitamin $\mathrm{E}$ concentration of RBO ranged from 10.02 to $15.29 \%$, 450.27 to $900.013 \mathrm{mg} . \mathrm{L}^{-1}$, and 120.51 to $129.83 \mathrm{mg} . \mathrm{L}^{-1}$, respectively (Tab. 2). The maximum of the oil yield, $\gamma$-oryzanol, and vitamin $\mathrm{E}$ concentration of RBO has been achieved at the optimum conditions of $x_{1}=5.30 \mathrm{~h}, x_{2}=89.21 \%$ and $x_{3}=686.66 \mathrm{~mL}$ ( $50 \mathrm{~g}$ rice bran), respectively. Maximum oil yield, $\gamma$-oryzanol, and vitamin $\mathrm{E}$ concentration of RBO under these conditions were $14.47 \%, 783.65 \mathrm{mg} . \mathrm{L}^{-1}$, and $127.01 \mathrm{mg} . \mathrm{L}^{-1}$, respectively. The experimental data were fitted with the secondorder equation model suggested by Design Expert 10 software.

\subsection{Model fitting}

The quality of the model developed was evaluated based on the correlation coefficient value. According to the result of ANOVA for oil yield, $\gamma$-oryzanol, and vitamin $E$ of $\mathrm{RBO}$, the $\mathrm{R}^{2}$ values of oil yield, $\gamma$-oryzanol, and vitamin $\mathrm{E}$ were $0.89,0.83$, and 0.84 , respectively, indicating that the models adequately represented the real relationship between the parameters chosen. According to Singh et al. (2018), when $\mathrm{R}^{2}$ is more than $80 \%$, the regression model shows good fit. The significance of different terms of each coefficient was determined using the $F$-value and $p$-value. According to Yolmeh et al. (2014), a large $F$-value and a small $p$-value would imply a more significant effect on the corresponding response variable. According to $\mathrm{Li}$ et al. (2014), the model is important and can be used to navigate the design domain. The model will be significant at a $95 \%$ confidence interval if the $F$ test has a $p$-value of less than 0.05 . In the case of lack-of-fit $(p>F)$, the $p$-value is greater than 0.05 which shows the failure of the model in finding data points in the experimental domain. The reduced quadratic model equation developed from the experimental data to predict the oil yield, $\gamma$-oryzanol, and vitamin $\mathrm{E}$ of RBO in terms of coded factors are given in equations (3-5), respectively.

$$
\begin{aligned}
\text { Oil yield }(\%)= & 13.40+0.14 x_{1}+0.52 x_{2}+0.98 x_{3} \\
& -1.14 x_{1} x_{2}+0.66 x_{2} x_{3}-0.69 x_{1}^{2}
\end{aligned}
$$




$$
\begin{aligned}
\gamma-\operatorname{oryzanol}\left(\mathrm{mg} . \mathrm{L}^{-1}\right) & =811.98+45.73 x_{1}-8.85 x_{2} \\
& +15.48 x_{3}-69.22 x_{2}^{2}-60.57 x_{3}^{2} \\
& \\
\operatorname{vitamin} \mathrm{E}\left(\mathrm{mg} . \mathrm{L}^{-1}\right) & =126.60+1.44 x_{1}+1.18 x_{2} \\
& -2.2 x_{1}^{2}-1.99 x_{2}^{2}
\end{aligned}
$$

where: $x_{1}=$ time; $x_{2}=$ ethanol concentration; $x_{3}=$ ethanol volume.

\section{2 interpretation result of ANOVA}

\subsubsection{Extraction yield of $\mathrm{RBO}$}

The result of ANOVA for response surface reduced quadratic model of the oil yield showed that the model $F$-value of 9.99 implies the model is significant. Values of Prob $>F$ of 0.0003 (less than 0.05 ) indicate model terms are significant. Values of Prob $>F$ less than 0.05 indicate variable terms are significant, in this case, the linear term of ethanol concentration $\left(x_{2}\right)$, the linear term of ethanol volume $\left(x_{3}\right)$, the quadratic terms of extraction time $\left(x_{1}{ }^{2}\right)$, the interaction between extraction time and ethanol concentration $\left(x_{1} x_{2}\right)$, and the interaction between ethanol concentration and ethanol volume $\left(x_{2} x_{3}\right)$ are significant variables terms. On the contrary, values Prob $>F$ greater than 0.1000 indicate the variable terms are not significant, in this case, the linear term of extraction time $\left(x_{1}\right)$, the quadratic terms of ethanol concentration $\left(x_{2}^{2}\right)$, the quadratic terms of ethanol volume $\left(x_{3}{ }^{2}\right)$, and interaction between extraction time and ethanol volume $\left(x_{1} x_{3}\right)$ did not give any significant contribution on oil yield.

The lack-of-fit $F$-value of 1.69 implies the lack-of-fit is not significant relative to the pure error. Non-significant lack-of-fit is good, which indicates that the model is suitable to describe the effect of variables for the oil yield and that the developed model was adequate for predicting the response. According to Bas and Boyaci, (2007), the model will be considered appropriate if the lack-of-fit value model is not significantly different at the level of specific $\alpha$. Further, according to Bezerra et al. (2008), a model will be well fitted to the experimental data if it presents a significant regression and a non-significant lack-of-fit. These values would give a relatively good fit to the mathematic model in terms of coded factors are given in equation (3).

In this study obtained a yield of RBO was $14.47 \%$ in agreement with the previous study. Anwar et al. (2005) has reported that the rice bran contained $15-20 \%$ oil, and $10-$ $26 \%$ according to Pourali et al. (2009). The simplest method of solvent extraction is the single contact batch operation, where the solid to be leached and the solvent is mixed and the extract solution and raffinate solid phases are separated (Bessa et al., 2017). Considering the time effect, it greatly affects the yield, especially on the value of the mass transfer. The longer the contact time between the solvent with the solute during the extraction process, the more the number of elements extracted chemical content. The more time is given for contact of the sample with the solvent, the higher the extraction yield percentage (Elkhaleefa and Shigidi, 2015). The effect of solvent concentration on the yield was also explained by Chen et al. (2016), that the extraction yield was increased with the increase of ethanol concentration in the extraction solvent.

The effect of volume of solvent is consistent with mass transfer principles. The driving force during mass transfer is the concentration gradient between the solid and the bulk of the liquid, which is greater when a higher solvent to solid ratio is used. Distribution of solvent to solids will greatly affect oil yield, the ratio solids with a solvent will affect the oil yield. The amount of solvent affects the wide contact between solids and solvents. The more solvent, the greater the contact area, so the distribution of the solvent will be even greater. Equitable distribution of solvent to solids increases the oil yields, the amount of solvent will reduce the saturation level of the solvent so that the desired component will be extracted perfectly. In general, the yield increased with increasing volume of the solvent used. The more the volume of solvent used, the greater the ability of a solvent to extract oil contained in the material. The increasing volume of solvent also leads to increasing contact time, which occurs between materials with a solvent.

In the extraction process, an optimum point will be reached. Mas'ud et al. (2017) conducted a study of the effects of extraction time, temperature, and volume of solvent in mango seed kernel oil extraction above room temperature, they reported that the variables had a significant effect on oil yield. Effect of the combination of reactions between variable time and temperature at high-level experimental process will obviously result in a decrease in oil yield. Similar phenomena have also been reported by Oniya et al. (2017) and Pichai and Krit (2015). A decrease in oil yield at high temperatures and long periods of time in oil extraction is thought to be a result of degradations of some oil components such as phenolic compounds degradations as reported by Chew et al. (2011). They conducted a study of the effects of ethanol concentration, extraction time, and extraction temperature on the recovery of phenolic compounds and antioxidant capacity, they were reported that the extraction time of 120 min was achieved the maximum concentration of phenolic compounds, and after this point, total phenolic content and thick tannin content were decreased. According to Chirinos et al. (2007), oxidation of phenolic compounds due to excessive oxygen exposure can occur if the extraction time is longer.

\subsection{2 $\gamma$-Oryzanol concentration of RBO}

The Model $F$-value of 4.62 implies the model is significant. Values of Prob $>F$ of 0.0106 (less than 0.05 ) indicate model terms are significant. Variables that have a significant effect on $\gamma$-oryzanol concentration were the quadratic terms of ethanol concentration $\left(x_{2}{ }^{2}\right)$ and the quadratic terms of ethanol volume $\left(x_{3}{ }^{2}\right)$. Values greater than 0.1000 indicate the model terms are not significant so that the linear term of extraction time $\left(x_{1}\right)$, ethanol concentration $\left(x_{2}\right)$, and ethanol volume $\left(x_{3}\right)$, the quadratic term of extraction time $\left(x_{1}{ }^{2}\right)$, the interaction between time and ethanol concentration $\left(x_{1} x_{2}\right)$, the interaction between time and ethanol volume $\left(x_{1} x_{3}\right)$, and the interaction between ethanol concentration and ethanol volume $\left(x_{2} x_{3}\right)$ did not give any significant contribution on $\gamma$-oryzanol concentration. The reduced quadratic model equation in terms of coded factors was developed from the experimental data to predict the $\gamma$-oryzanol of RBO produced from ANOVA as given in equation (4). The coefficient values of variables $x_{1}, x_{2}$, and $x_{3}$ 


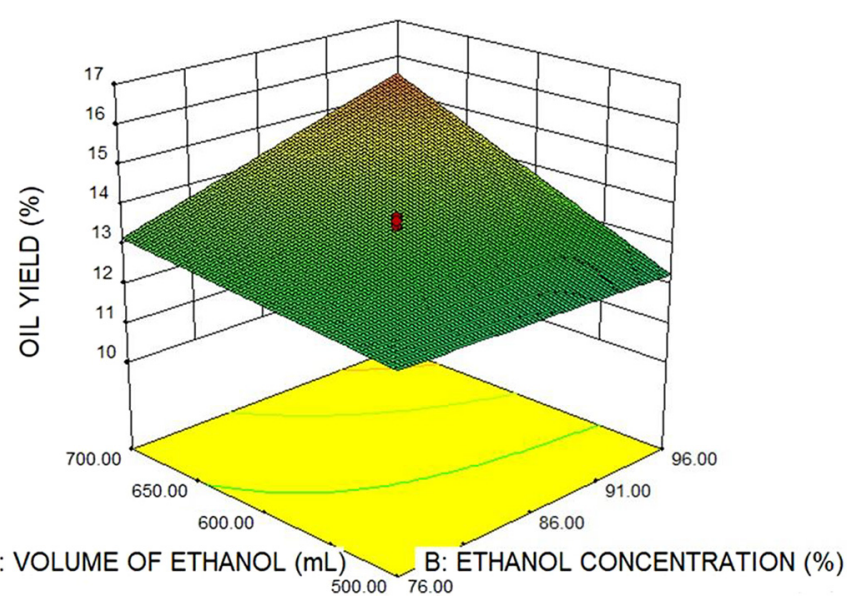

Fig. 1. Response surface plot of oil yield RBO at a fixed extraction time of $5 \mathrm{~h}$.

still appear in the model because the Design Expert 10 software work system used was hierarchical, so that if the quadratic effect is significant then the linear effect will also appear in the model even though the linear effect is not significant based on the ANOVA results. The lack-of-fit $F$-value of 2.90 implies the lack-of-fit is not significant relative to the pure error. This indicates that the model is suitable to describe the effect of a parameter observed on $\gamma$-oryzanol and that the developed model is adequate for predicting the response.

In this study obtained a $\gamma$-oryzanol of $783.65 \mathrm{mg} . \mathrm{L}^{-1}$. According to Arab et al. (2011), RBO contains about 0.9-2.9\% of $\gamma$-oryzanol, 1.5 to $2.9 \%$ according to Krishna et al. (2001), $119.75-281.95 \mathrm{mg} . \mathrm{g}^{-1}$ oil according to Sukanya et al. (2017), $3.33 \mathrm{~g} .100 \mathrm{~g}^{-1}$ according to Al-Okbi et al. (2014), even up to $3000 \mathrm{mg} \cdot \mathrm{kg}^{-1}$ according to Shin et al. (1997). $\gamma$-oryzanol extracted with 3:2 chloroform: methanol mixture yielding 23.7-43.0 mg. $\mathrm{g}^{-1}$ in the crude RBO (Azrina et al., 2008). According to Iqbal et al. (2005), the exact composition of $\gamma$-oryzanol depends on the rice cultivars. Furthermore, according to Butsat and Siriamornpun, (2010), that the content of $\gamma$-oryzanol in rice affected by the variety and growing conditions, as the antioxidant component will respond differently to environmental changes.

The effect of different solvent concentrations can produce different yields have been also explained by Cacace and Mazza (2003), that the change in concentration in the solvent will modify the physical properties of the solvent such as density, dynamic viscosity, and dielectric constant. The solubility of the compound will also be modified by changes in solvent concentration, and this can affect yield. According to JaponLujan et al. (2006), 80\% aqueous ethanol (v/v) was the optimum solvent for extraction of the targeted phenolics from olive leaf and it can be used as a replacement of toxic solvents (methanol, diethyl ether, chloroform) to obtain bioactive phenols for human use. Further, according to Malik and Bradford (2008), extraction with $80 \%$ methanol (v/v) was reported as the most effective method for olive leaves polyphenols. Related to the amount of solvent, the ratio of solvents to solids used by researchers for extraction varies greatly from 4 to 100 , but the ratio between 10 and 50 is mostly reported in the literature (Kiritsakis et al., 2010).

\subsubsection{Vitamin E concentration of RBO}

The result of ANOVA for response surface reduced quadratic model of vitamin E showed that the model $F$-value of 10.86 implies the model is significant. Values of Prob $>F$ of 0.0002 (less than 0.05) indicate model terms are significant. In this case, the linear terms of extraction time $\left(x_{1}\right)$, the linear terms of ethanol concentration $\left(x_{2}\right)$, the quadratic term of extraction time $\left(x_{1}^{2}\right)$, and the quadratic term of ethanol concentration $\left(x_{2}{ }^{2}\right)$. Values greater than 0.1000 indicate the model terms are not significant, so that the linear term of ethanol volume $\left(x^{3}\right)$, the quadratic term of ethanol volume $\left(x_{3}{ }^{2}\right)$, the interaction between extraction time and ethanol concentration $\left(x_{1} x_{2}\right)$, the interaction between extraction time and ethanol volume $\left(x_{1} x_{3}\right)$, and the interaction between ethanol concentration and ethanol volume $\left(x_{2} x_{3}\right)$ did not give any significant contribution on vitamin E concentration. The lackof-fit $F$-value of 2.26 implies the lack-of-fit is not significant relative to the pure error, this indicates that the model is suitable to describe the effect of variable observed for the vitamin $\mathrm{E}$ and that the developed model is adequate for predicting the response.

In this study obtained a vitamin $\mathrm{E}$ of $127.01 \mathrm{mg} . \mathrm{L}^{-1}$. According to $\mathrm{Xu}$ et al. (2007), RBO contains $0.37-1.84 \mathrm{mg}$. $\mathrm{g}^{-1}$ oil, $170-218 \mu \mathrm{g} \cdot \mathrm{g}^{-1}$ according to Schramm et al. (2007) and $665 \mu \mathrm{g} \cdot \mathrm{g}^{-1}$ according to Al-Okbi et al. (2014). Shortchain alcohols, especially ethanol and isopropanol, have been proposed as alternative extraction solvents due to their greater safety. Alcohols tend to extract more non-glyceride materials than n-hexane, due to their greater polarity. Typically, alcoholextracted oils contain more phosphatides and unsaponifiable compounds (Lusas et al., 1991). Further, Hu et al. (1996) reported that the average amount of vitamin E of RBO with isopropanol extraction was greater than that with hexane extraction and related to the amount of solvent, an increase in isopropanol-to-bran ratio (w/w) from $2: 1$ to $3: 1$ extracted $9.4 \%$ more crude RBO that contained $10 \%$ more vitamin $\mathrm{E}$ which explains that the amount of solvent affects the extraction of vitamin E. They also reported that the extraction time did not have a significant effect on the amount of $\mathrm{RBO}$ or vitamin $\mathrm{E}$ extracted.

\subsection{Interpretation of response surface and contour plots}

Based on the fitted model, the response surface and contour plots were generated by the model for extraction of oil yield, $\gamma$-oryzanol, and vitamin E of RBO as a response. In order to gain a better understanding of this study, related to the effect of observed variables on the response, then the predicted models are presented as the $3 \mathrm{D}$ plot (Figs. 1-3, respectively). Response surface plot is a representation of the surface plot in 3-D space as the plot determining optimum operating conditions reaching maximum from the best-fitted model. These plots are obtained depicting two variables within experimental range and keeping the third variable at a constant level. According to Bezerra et al. (2008), a two-dimensional representation of a three-dimensional plot can be explained. If there are three or more variables, the plot visualization is possible only if one or more variables are set to a constant value. 


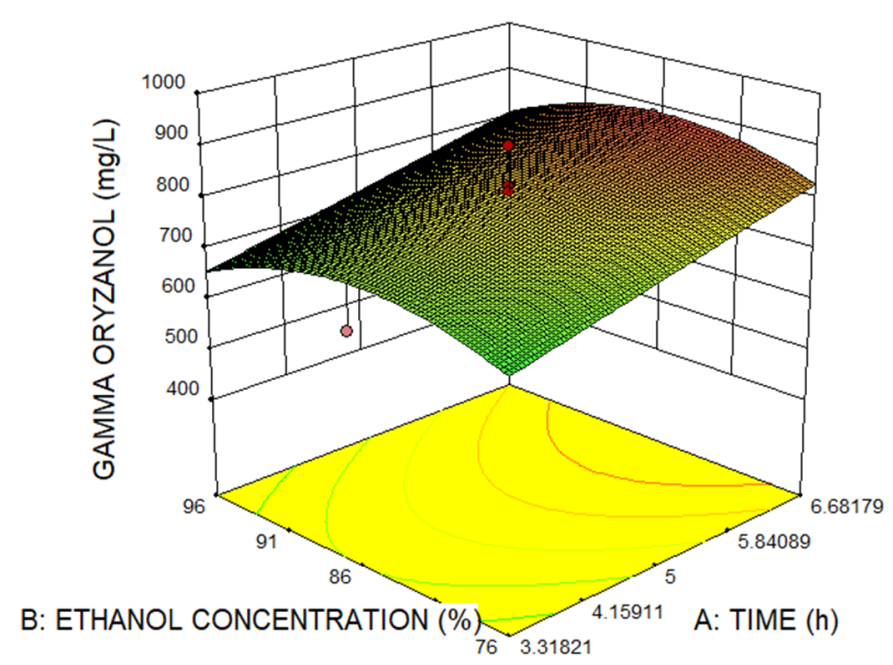

Fig. 2. Response surface plot of $\gamma$-oryzanol RBO at a fixed ethanol volume of $600 \mathrm{~mL}$.

Figure 1 shows a 3D plot corresponding to the effect of $x_{2}$ and $x_{3}$ on oil yield at the fixed of $x_{1}(5 \mathrm{~h})$. The effect of $x_{3}$ is stronger than the effect of $x_{2}$ on increasing the oil yield. It is evident in the coefficient variable of $x_{2}$ and $x_{3}$, where coefficient variable of $x_{3}>x_{2}$, and it is evident in the coefficient estimate of the ANOVA, where the coefficient variable in term of actual factor of $x_{3}(0.98)$ is higher than $x_{2}(0.52)$, while the effect of $x_{1}$ is not significant in increasing the yield of the RBO, the estimated coefficient of $x_{1}$ is 0.14 .

The plot that discloses the effects of $x_{1}$ and $x_{2}$ on increasing $\gamma$-oryzanol of RBO at a fixed of $x_{3}(600 \mathrm{~mL})$ is shown in Figure 2. It can be seen that the $\gamma$-oryzanol had a maximum point. The combination of variables observed is an effect on increasing the $\gamma$-oryzanol of RBO. At $x_{3}$ constant $(600 \mathrm{~mL})$, the influence of $x_{2}$ is stronger than the effect of $x_{1}$ on increased of the $\gamma$-oryzanol. It is evident in the 3D plot that the curve at $x_{2}$ is more convex than the curve at $x_{1}$, meaning that a small change in $x_{2}$ has greatly affected the acquisition of $\gamma$-oryzanol.

The 3D plot corresponding to explain the effect of $x_{1}$ and $x_{2}$ on the vitamin $\mathrm{E}$ at a fixed of $x_{3}(600 \mathrm{~mL})$ is shown in Figure 3. It is showed that the vitamin $\mathrm{E}$ had a maximum point. $x_{1}$ and $x_{2}$ were effects on increasing the vitamin E. At $x_{3}$ constant $(600 \mathrm{~mL})$, the effect of $x_{1}$ is very strong compared to the effect of $x_{2}$ on the acquisition of vitamin E. It can also be proved from the coefficients of $x_{1}$ and $x_{2}$ in equation (5), where the value of coefficient $x_{1}>x_{2}$.

\subsection{Interpretation of the optimum conditions}

Based on the optimization solution generated from the Design Expert 10 software that the optimum of $x_{1}, x_{2}$, and $x_{3}$ to obtain the maximum of oil yield, $\gamma$-oryzanol, and vitamin $\mathrm{E}$ of RBO can be achieved at $x_{1}$ of $5.30 \mathrm{~h}, x_{2}$ of $89.21 \%$, and $x_{3}$ of $686.66 \mathrm{~mL}$. It can be explained that an increase $x_{1}$ of $4 \mathrm{~h}$ to $5.30 \mathrm{~h}$ and $x_{2}$ of $76 \%$ to $89.21 \%$ (at fixed $x_{3}$ of $600 \mathrm{~mL}$ ) cause an increase in the oil yield, $\gamma$-oryzanol, and vitamin $E$ of RBO.

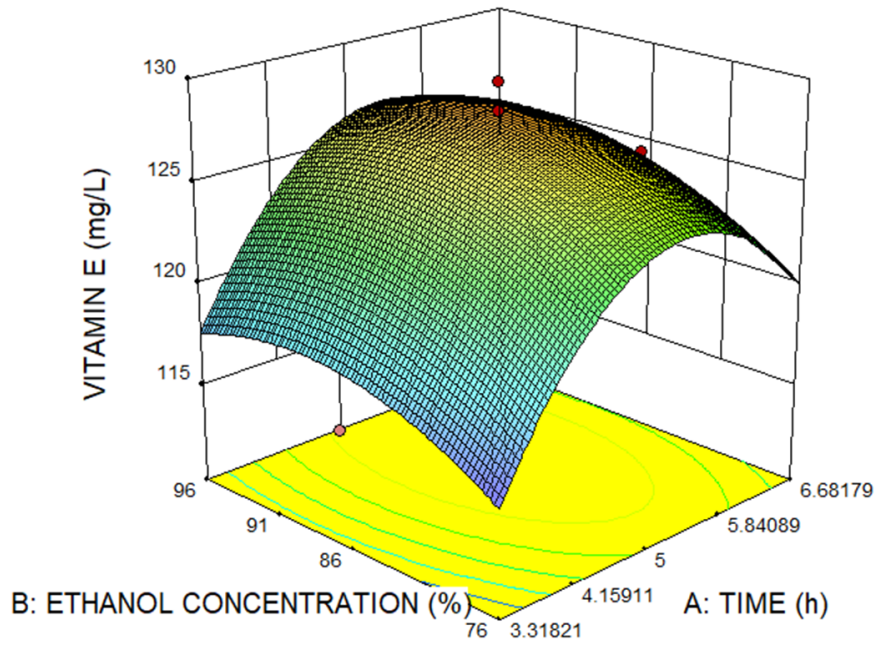

Fig. 3. Response surface plot of vitamin $\mathrm{E}$ RBO at a fixed ethanol volume of $600 \mathrm{~mL}$.

The addition of $x_{1}$ of $5.30 \mathrm{~h}$ up to $6 \mathrm{~h}$ and addition $x_{2}$ of $89.21 \%$ up to $98 \%$ did not cause an increase in oil yield, $\gamma$-oryzanol, and vitamin $\mathrm{E}$ of $\mathrm{RBO}$.

The same explanation at fixed $x_{1}$ of $5 \mathrm{~h}$, an increase of $x_{2}$ of $76 \%$ to $89.21 \%$, and $x_{3}$ of $500 \mathrm{~mL}$ to $686.66 \mathrm{~mL}$ cause an increase in the oil yield, $\gamma$-oryzanol, and vitamin $\mathrm{E}$ of RBO. Further, increasing $x_{2}$ of $89.21 \%$ up to $96 \%$, and addition $x_{3}$ of $686.66 \mathrm{~mL}$ up to $700 \mathrm{~mL}$ did not cause an increase in the oil yield, $\gamma$-oryzanol, and vitamin $\mathrm{E}$ of $\mathrm{RBO}$. The same phenomenon at fixed $x_{2}$ of $86 \%$, an addition of $x_{1}$ of $4 \mathrm{~h}$ to $5.30 \mathrm{~h}$, and $x_{3}$ of $500 \mathrm{~mL}$ up to $686.66 \mathrm{~mL}$ cause an increase in the oil yield, $\gamma$-oryzanol, and vitamin $\mathrm{E}$ of RBO. The addition of $x_{1}$ of $5.30 \mathrm{~h}$ up to $6 \mathrm{~h}$ and addition $x_{2}$ of $89.21 \%$ up to $98 \%$ did not cause an increase in the oil yield, $\gamma$-oryzanol, and vitamin $\mathrm{E}$ of $\mathrm{RBO}$.

\subsection{Verification model}

An optimization model of RBO extraction by maceration method with stirring has been developed. The laboratory scale for verification of the model has been carried out by conducting triplicate experiments using the recommended value of variables from the software. The result showed that the average oil yield, $\gamma$-oryzanol, and vitamin $\mathrm{E}$ were $13.91 \% \pm 0.44, \quad 775.36 \pm 31.38$, and $126.71 \pm 0.61 \mathrm{mg} . \mathrm{L}^{-1}$, respectively. The RBO produced in the verification process showed that the average value of the oil yield, $\gamma$-oryzanol, and vitamin $\mathrm{E}$ was close to the predicted values $(14.47 \%$, $783.65 \mathrm{mg} . \mathrm{L}^{-1}$, and $127.01 \mathrm{mg} . \mathrm{L}^{-1}$, respectively). This indicates that the model developed is quite valid in their predictions.

\section{Conclusions}

RBO extraction use ethanol by maceration method accompanied by stirring is very promising to be applied in the industry, as an effort to implement the concept of green solvents that are safe for consumers and the environment. The 
effect of extraction time, ethanol concentration, and ethanol volume on the oil yield, $\gamma$-oryzanol, and vitamin E of RBO has been evaluated. Ethanol can be used to extract RBO without involving heating and proven to be able to provide satisfactory results. The optimization of the extraction process has been developed and verified at the laboratory scale with sufficient results. Predictive values produced by a model that approaches the actual value have proven that the model developed is quite valid and feasible to be applied in the RBO extraction process.

Acknowledgments. The authors would like to thank the Higher Education Ministry of Indonesia (DIKTI) and Department of Chemical Engineering, Politeknik Negeri Ujung Pandang, Makassar, Indonesia.

Conflicts of interest. The authors declare that they have no conflicts of interest in relation to this article.

\section{References}

Al-Okbi SY, Ammar NM, Mohamed DA, et al. 2014. Egyptian rice bran oil: Chemical analysis of the main phytochemicals. Riv Ital Sostanze Gr 91: 47-58.

Amiri H, Nabizadeh R, Martinez SS, et al. 2018. Response surface methodology modeling to improve degradation of Chlorpyrifos in agriculture runoff using $\mathrm{TiO}_{2}$ solar photocatalytic in a raceway pond reactor. Ecotoxicol Environ Saf 147: 919-925. DOI: 10.1016/j.ecoenv.2017.09.062.

Anwar F, Tabreez A, Zahid M. 2005. Methodical characterization of rice (Oryza sativa) bran oil from Pakistan. Grasas Aceites 56 Fasc. 2: 125-134.

Arab F, Alemzadeh I, Maghsoudi V. 2011. Determination of antioxidant component and activity of rice bran extract. Scientia Iranica 18(6): 1402-1406. DOI: 10.1016/j.scient.2011.09.014.

Awad OI, Mamat R, Ali OM, et al.2017. Response surface methodology (RSM) based multi-objective optimization of fusel oil-gasoline blends at different water content in SI engine. Energy Convers Manag 150: 222-241. DOI: 10.1016/j.enconman.2017.07.047.

Azrina A, Maznah I, Azizah AH. 2008. Extraction and determination of oryzanol in rice bran of mixed herbarium UKMB; AZ 6807: MR 185, AZ 6808: MR 211, A Z6809: MR 29. ASEAN Food J 15 (1): 89-96.

Banga J, Tripathi CKM. 2009. Response surface methodology for optimization of medium components in submerged culture of Aspergillus flavus for enhanced heparinase production. Lett Appl Microbiol 49: 204-209. DOI: 10.1111/j.1472-765X.2009.02640.x.

Bas D, Boyaci IH. 2007. Modelling and optimization I: Usability of response surface methodology. J Food Eng 78: 836-845. DOI: 10.1016/j.jfoodeng.2005.11.024.

Bauernfeind JC, Desai ID. 1977. The tocopherol content of food and influencing factors. Crit Rev Food Sci Nutr 8: 337-382. DOI: 10.1080/10408397709527226.

Baümler ER, Carrín ME, Carelli AA. 2016. Extraction of sunflower oil using ethanol as solvent. J Food Eng 178: 190-197. DOI: 10.1016/j.jfoodeng.2016.01.020.

Bessa LCBA, Ferreira MC, Rodrigues CEC, Batista EAC, Meirelles AJA. 2017. Simulation and process design of continuous countercurrent ethanolic extraction of rice bran oil. J Food Eng DOI: 10.1016/j.jfoodeng.2017.01.019.

Bezerra MA, Santelli RE, Oliveira EP, Villar LS, Escaleira LA. 2008. Response surface methodology (RSM) as a tool for optimization in analytical chemistry. Talanta 76(5): 965-977. DOI: 10.1016/j. talanta.2008.05.019.
Butsat S, Siriamornpun S. 2010. Antioxidant capacities and phenolic compounds of the husk, bran and endosperm of Thai rice. Food Chem 119: 606-613. DOI: 10.1016/j.foodchem.2009.07.001.

Cacace JE, Mazza G. 2003. Optimization of extraction of anthocyanins from black currants with aqueous ethanol. J Food Sci 68(1): 240-248.

Chan YH, Yusup S, Quitain AT, Uemura Y, Loh SK. 2017. Fractionation of pyrolysis oil via supercritical carbon dioxide extraction: Optimization study using response surface methodology (RSM). Biomass Bioenergy 107: 155-163. DOI: 10.1016/j. biombioe.2017.10.005.

Chemat F, Vian MA, Cravotto G. 2012. Green extraction of natural products: Concept and principles. Int J Mol Sci 13: 8615-8627. DOI: $10.3390 /$ ijms 13078615 .

Chen MH, Bergman CJ. 2005. A rapid procedure for analyzing rice bran tocopherol, tocotrienol and gamma oryzanol contents. J Food Compos Anal 18: 139-151. DOI: 10.1016/j.jfca.2003.09.004.

Chen Qi, Fung Ka Y, Lau Yeuk T, Ng Ka M, Lau David TW. 2016. Relationship between maceration and extraction yield in the production of Chinese herbal medicine. Food Bioprod Process. DOI: 10.1016/j.fbp.2016.02.005.

Chew KK, Ng SY, Thoo YY, Khoo MZ, Wan Aida WM, Ho CW. 2011. Effect of ethanol concentration, extraction time and extraction temperature on the recovery of phenolic compounds and antioxidant capacity of Centella asiatica extracts. Int Food Res J 18: 571-578.

Chirinos R, Rogez H, Campos D, Pedreschi R, Larondelle Y. 2007. Optimization of extraction conditions of antioxidant phenolic compounds from mashua (Tropaeolum tuberosum Ruíz and Pavón) tubers. Sep Purif Technol 55(2): 217-225.

Desai ID, Swann MA, Garcia Tavares ML, Dutra de Oliveira BS, Duarte FAM, Dutra de Oliveira JE. 1980. Vitamin E status of agricultural migrant workers in Southern Brazil. Amer J Clin Nutr 33: 2669-2673. DOI: 10.1093/ajen/33.12.2669.

Elkhaleefa A, Shigidi I. 2015. Optimization of sesame oil extraction process conditions. Adv Chem Eng Sci 5: 305-310. DOI: 10.4236/ aces.2015.53031.

Firestone D. (Ed.). 1999. Physical and chemical characteristics of oils, fats, and waxes. Washington, DC: AOCS Press, pp. 86-87.

Hu W, Wells JH, Tai-Sun S, Godber JS. 1996. Comparison of isopropanol and hexane for extraction of vitamin $\mathrm{E}$ and oryzanois from stabilized rice bran. JAOCS 73(12): 1653-1656. DOI: 10.1007/BF02517967.

Iqbal S, Bhanger MI, Anwar F. 2005. Antioxidant properties and components of some commercially available varieties of rice bran in Pakistan. Food Chem 93: 265-272. DOI: 10.1016/j. foodchem.2004.09.024.

Imsanguan P, Roaysubtawee A, Borirak R, Pongamphai S, Douglas S, Douglas PL. 2008. Extraction of $\alpha$-tocopherol and $\gamma$-oryzanol from rice bran. Food Sci Technol 41: 1417-1424.

Japon-Lujan R, Luque-Rodriguez JM, DeCastro MDL. 2006. Multivariate optimisation of the microwave-assisted extraction of oleuropein and related biophenols from olive leaves. Anal Bioanal Chem 385(4): 753-759.

Keshtegar B, Mert C, Kisi O. 2018. Comparison of four heuristic regression techniques in solar radiation modeling: Kriging method vs. RSM, MARS and M5 model tree. Renew Sustain Energy Rev 81: 330-341. DOI: 10.1016/j.rser.2017.07.054.

Kiritsakis K, Kontominas MG, Kontogiorgis C, Hadjipavlou-Litina D, Moustakas A, Kiritsakis A. 2010. Composition and antioxidant activity of olive leaf extracts from greek olive cultivars. $J$ Am Oil Chem Soc 87(4): 369-376.

Krishna AGG, Khatoon S, Shielaa PM, Sarmandala CV, Indirab TN, Mishrac A. 2001. Effect of refining of crude rice bran oil on the retention of oryzanol in the refined oil. JAOCS 78(2): 127-131. 
Lerma-García MJ, Herrero-Martínez JM, Simó-Alfonso EF, Mendonça CRB, Ramis-Ramos G. 2009. Composition, industrial processing and applications of rice bran $\gamma$-oryzanol. Food Chem 115(2): 389-404. DOI: 10.1016/j.foodchem.2009.01.063.

Li L, Li X, Yan C, et al. 2014. Optimization of methyl orange removal from aqueous solution by response surface methodology using spent tea leaves as an adsorbent. Front Environ Sci Eng 8: 496502. DOI: $10.1007 / \mathrm{s} 11783-013-0578-0$.

Li Z, Smith KH, Stevens GW. 2016. The use of environmentally sustainable bio-derived solvents in solvent extraction applications - A review, Chin J Chem Eng 24: 215-220. DOI: 10.1016/j. cjche.2015.07.021.

Lusas EW, Watkins LR, Koseoglu SS. 1991. Isopropyl alcohol to be tested as solvent. Inform 2: 970-976.

Malik NSA, Bradford JM. 2008. Recovery and stability of oleuropein and other phenolic compounds during extraction and processing of olive (Olea europaea L.) leaves. J Food Agric Environ 6(2): 8-13.

Mas'ud F, Mahendradatta M, Amran L, Zainal Z. 2017. Optimization of mango seed kernel oil extraction using response surface methodology. Oilseeds Fats Crops Lipids. Available from www. ocl-journal.org. DOI: 10.1051/oc1/2017041.

Mohammed BS, Khed VC, Nuruddin MF. 2018. Rubbercrete mixture optimization using response surface methodology. J Clean Prod 171: 1605-1621. DOI: 10.1016/j.jclepro.2017.10.102.

Oliveira R, Oliveira V, Aracava KK, Rodrigues CEdC. 2012. Effects of the extraction conditions on the yield and composition of rice bran oil extracted with ethanol-A response surface approach. Food Bioprod Process 90(C1): 22-31. DOI: 10.1016/j. fbp.2011.01.004.

Oniya OO, Oyelade JO, Ogunkunle O, Idowu DO. 2017. Optimization of solvent extraction of oil from sandbox kernels (Hura Crepitans L.) by a response surface method. Energy Policy Res 4(1): 36-43, DOI: 10.1080/23815639.2017.1324332.

Pichai E, Krit S. 2015. Optimization of solid-to-solvent ratio and time for oil extraction process from spent coffee grounds using response surface methodology. ARPN J Eng App Sci 10(16): 7049-7052.

Péres VF, Maria JS, Melecchi IS, et al. 2006. Comparison of soxhlet, ultrasound-assisted and pressurized liquid extraction of terpenes, fatty acids and Vitamin E from Piper gaudichaudianum Kunth. $J$ Chromatogr A 1105(1-2 SPEC. ISS.): 115-118. DOI: 10.1016/j. chroma.2005.07.113.

Pourali O, Feridoun SA, Hiroyuki Y. 2009. Simultaneous rice bran oil stabilization and extraction using sub-critical water medium. $J$ of Food Eng 95: 510-516. DOI: 10.1016/j.jfoodeng.2009.06.014.

Rafi NM, Halim NRA, Amin AM, Sarbon NM. 2015. Response surface optimization of enzymatic hydrolysis conditions of lead tree (Leucaena leucocephala) seed hydrolyzate. Int Food Res J 22 (3): 1015-1023.

Rodrigues CEC, Oliveira R. 2010. Response surface methodology applied to the analysis of rice bran oil extraction process with ethanol. Int J Food Sci Technol 45(4): 813-820. DOI: 10.1111/ j.1365-2621.2010.02202.x.

Rogers EJ, Rice SM, Nicolosi RJ, Carpenter DR, McClelland CA, Romanczyk LJ Jr. 1993. Identification and quantitation of $\gamma$ oryzanol components and simultaneous assessment of tocols in rice bran oil. JAOCS 70(3): 301-307.
Sani I. 2014. Soxhlet extraction and physicochemical characterization of Mangifera indica L. Seed kernel oil. Res Rev: J Food Dairy Tech 2(1): 20-24.

Saxena DK, Sharma SK, Sambi SS. 2011. Comparative extraction of cottonseed oil by n-hexane and ethanol. ARPNJ Eng App Sci 6(1): 84-89.

Schramm RC, Alicia M, Na H, Marybeth L. 2007. Fractionation of the rice bran layer and quantification of vitamin E, oryzanol, protein, and rice bran saccharide. J Biol Eng 1(1): 9. DOI: 10.1186/ 1754-1611-1-9.

Seema P. 2015. Cereal bran fortified-functional foods for obesity and diabetes management: Triumphs, hurdles and possibilities. $J$ Funct Foods 14: 255-269.

Shin T, Godber JS, Martin DE, Wells JH. 1997. Hydrolitic stability and changes in $\mathrm{E}$ vitamers and oryzanol of extruded rice bran during storage. J Food Sci 62: 704-708.

Singh V, Belova L, Singh B, Sharma YC. 2018. Biodiesel production using a novel heterogeneous catalyst, magnesium zirconate $\left(\mathrm{Mg}_{2} \mathrm{Zr}_{5} \mathrm{O}_{12}\right)$ : Process optimization through response surface methodology (RSM). Energy Convers Manag 174: 198-207. DOI: 10.1016/j.enconman.2018.08.029.

Soundararajan R, Ramesh A, Mohanraj N, Parthasarathi N. 2016. An investigation of material removal rate and surface roughness of squeeze casted A413 alloy on WEDM by multi response optimization using RSM. J Alloys Compd 685: 533-545. DOI: 10.1016/j.jallcom.2016.05.292.

Sukanya M, Aikkarach K, Khongsak S, Riantong S. 2017. Physicochemical and antioxidant properties of rice bran oils produced from colored rice using different extraction methods. $J$ Oleo Sci 66(6): 565-572. DOI: 10.5650/jos.ess17014.

Tan YH, Abdullah MO, Hipolito CN, Syuhada N, Zauzi A. 2017. Application of RSM and Taguchi methods for optimizing the transesterification of waste cooking oil catalyzed by solid ostrich and chicken-eggshell derived $\mathrm{CaO}$. Renewable Energy 114: 437447. DOI: 10.1016/j.renene.2017.07.024.

Tekin K, Hao N, Karagoz S, Ragauskas AJ. 2018. Ethanol: A promising green solvent for the deconstruction of lignocellulose. ChemSusChem. DOI: 10.1002/cssc.201801291.

Tiwari U, Cummins E. 2009. Nutritional importance and effect of processing on tocols in cereals. Trends Food Sci Technol 20: 511520. DOI: 10.1016/j.tifs.2009.06.001.

Xu Z, Godber JS. 2001. Comparison of supercritical fluid and solvent extraction methods in extracting gamma-oryzanol from rice bran. J Am Oil Chem Soc 77: 1127-1131. DOI: 10.1007/s11746-0000087-4.

Xu Z, Hua N, Godber JS. 2001. Antioxidant activity of tocopherols, tocotrienols, and gamma oryzanol components from rice bran against cholesterol oxidation accelerated by 2, 2'-Azobis (2methylpropionamidine) dihydrochloride. J Agr Food Chem 49: 2077-2081. DOI: 10.1021/jf0012852.

Xu YX, Hanna MA, Josiah SJ. 2007. Hybrid hazelnut oil characteristics and its potential oleochemical application. Ind Crops Prod 26(1): 69-76. DOI: 10.1016/j.indcrop.2007.01.009.

Yolmeh M, Habibi Najafi MB, Farhoosh R. 2014. Optimisation of ultrasound-assisted extraction of natural pigment from annatto seeds by response surface methodology (RSM). J Food Chem 155: 319-324. DOI: 10.1016/j.foodchem.2014.01.059.

Cite this article as: Mas'ud F, Fajar, Bangngalino H, Indriati S, Todingbua A, Suhardi, Sayuti M. 2019. Model development to enhance the solvent extraction of rice bran oil. $O C L$ 26: 16. 